\section{H th}

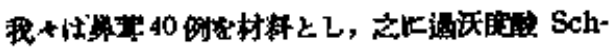

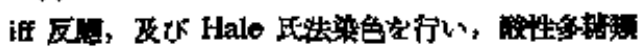

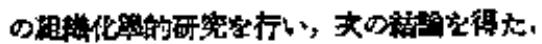

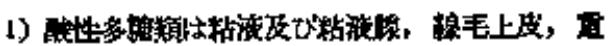

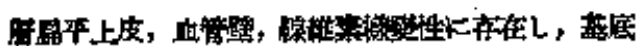

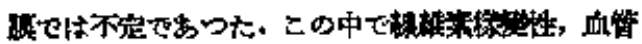

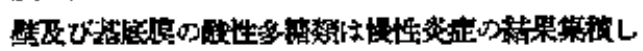
た尚のと思如名。

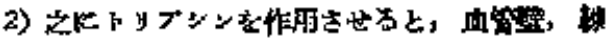

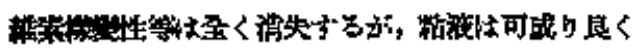

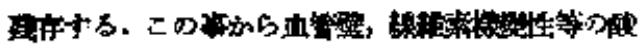

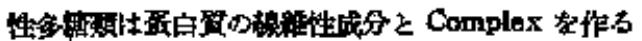

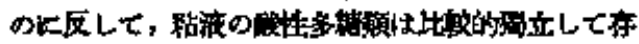

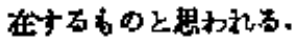

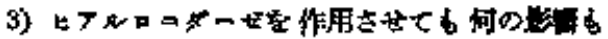

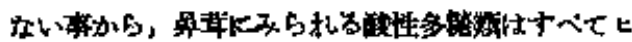

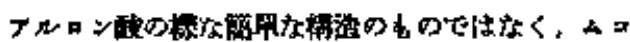

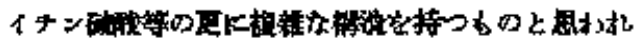
る.

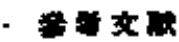

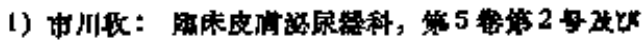
货 3 톰. 2) Attschuler: Am. J. of Path. Bd. 27, No. I. p. 141, 195!, 3) Hate: Hature; 157. $802,1946.4$ 4) Hoththiss: Arch, Bio" Chem. Bd. 16, p. 131, 1946. 5) Lilite: Anat. Rec. Vol. 108, No. 2, 1950. 6) MC. Monus, Am. J. of Path, Vol, 24, No. 3, p. 643, 1948. 7) Mf. Mants: Nature, 159; 202, 1946, B) Mc. Manus: Am. J. of Path. Vol, 26, (2), p. 690, 1950. 9) Rinehart: Arch of Path. Bd. 51, p. 12, 1951, 10) Rituliart: Arch. of Path. Vol. 52, No. 2 p 189, 1951.

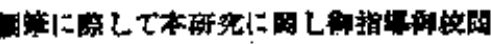

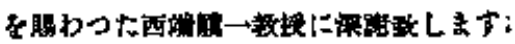

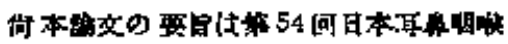

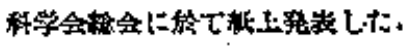

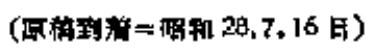

T. TOMITA, M:D.: EXPERIMÉNTAL STUDIES ON THE ABSORPTIVE FUNCTION OF THE TYMPANIC CAVITY IN INFANT ANIMALS (HISTOPATHOLOGICAL STUDY)

First Report: On the Absorptive Function of the Tyrpanic Cavity in Normal Intant Animal

\section{奻若動物の中耳吸收機能に閶する研究 (病理 組 織學 的研 究)}

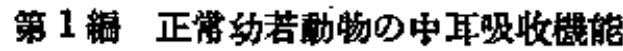

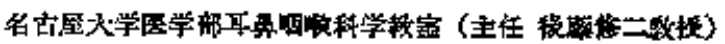

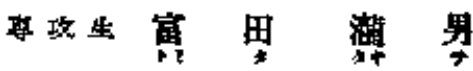

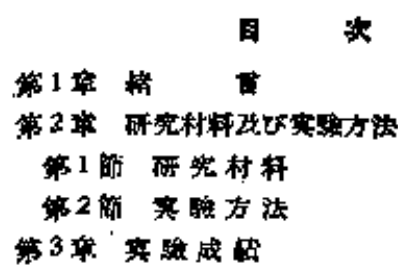

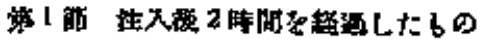

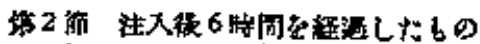

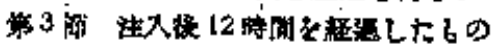

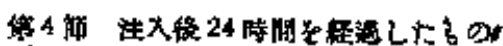

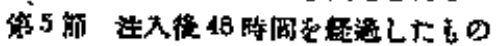
整4 章括 
M12:

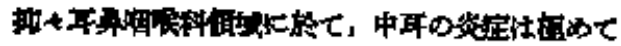

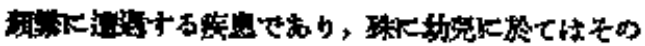

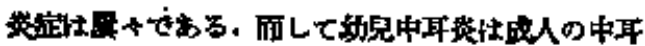

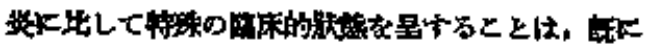

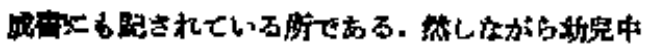

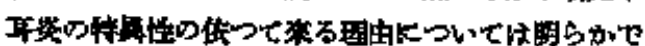

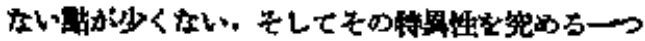

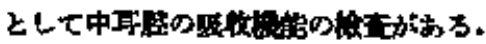

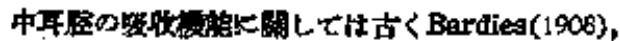

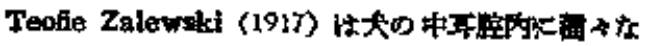

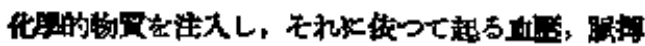

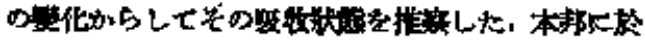

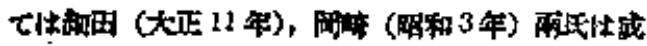

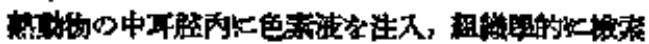

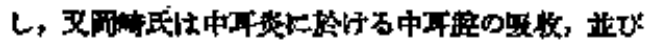

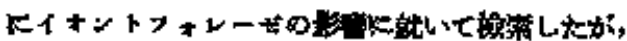

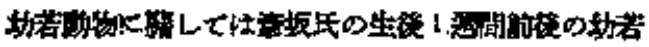

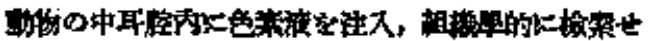

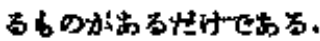

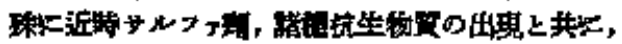

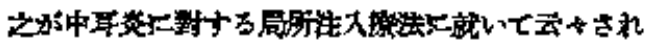

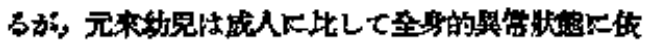

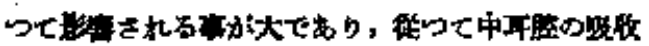

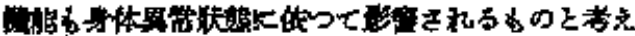

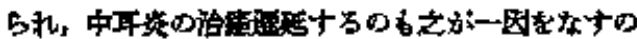

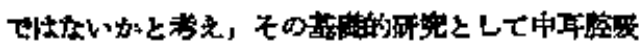

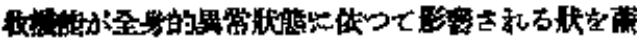

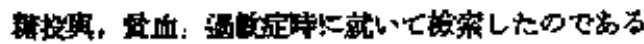

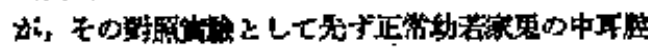

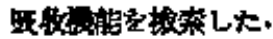

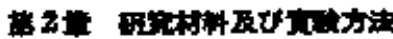

管1 解研究材料

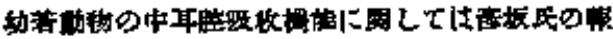

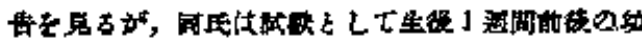

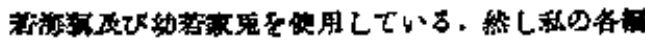

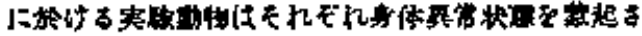

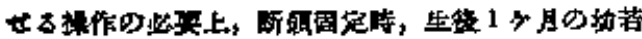

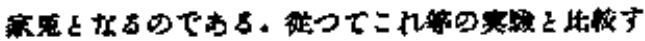

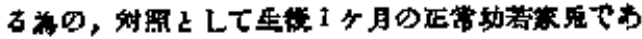

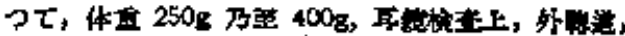

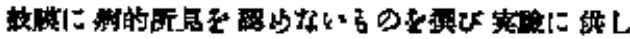
t.

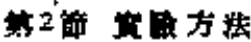

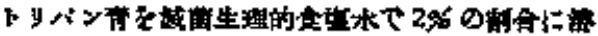

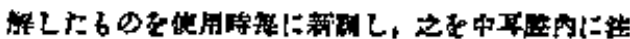

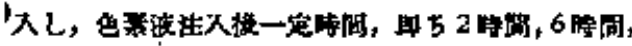

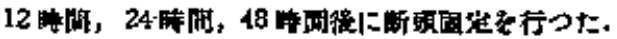

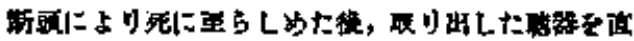

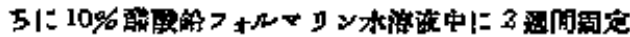

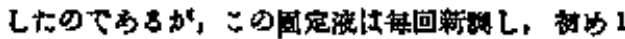

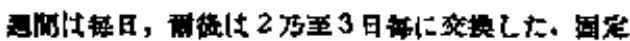

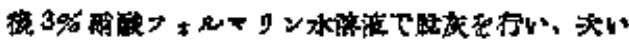

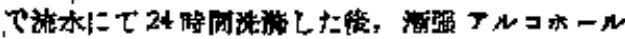

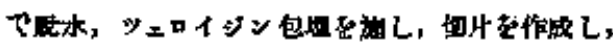

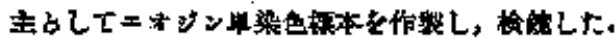

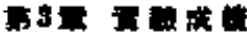

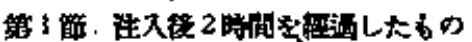
(Na. 92).

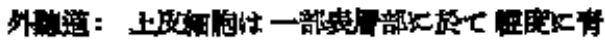

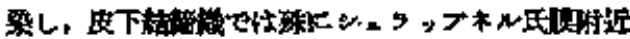

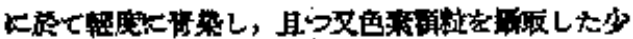

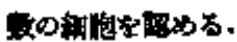

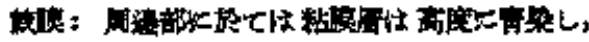

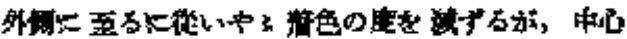

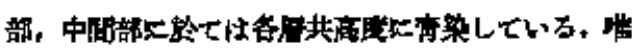

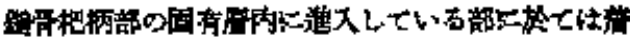

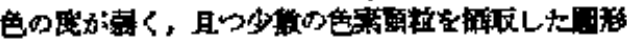

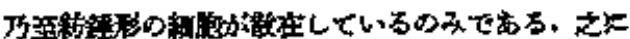

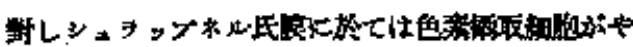

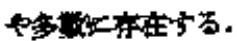

\section{中 I:}

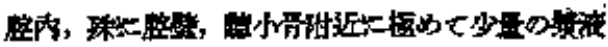

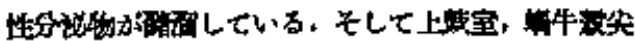

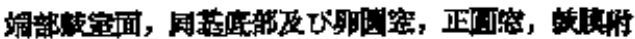

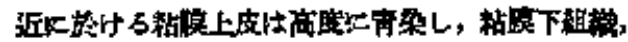

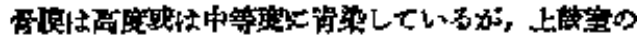

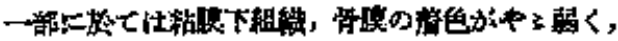

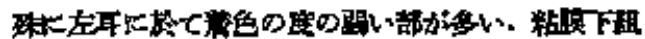

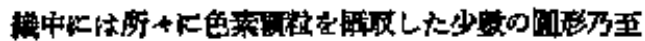

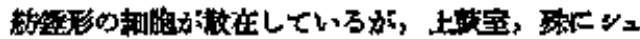




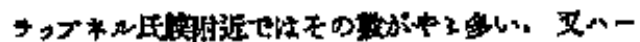

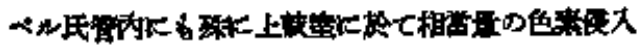
を龍める.

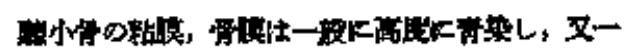

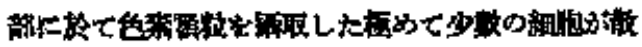

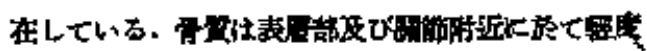

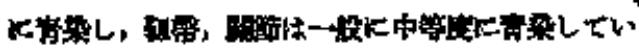

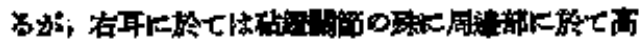

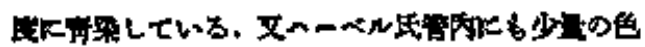

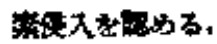

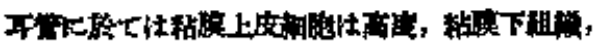

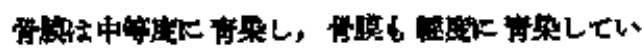
s.

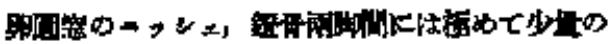

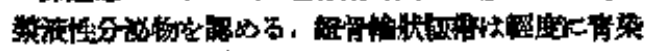

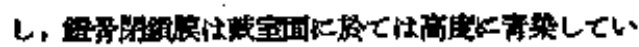

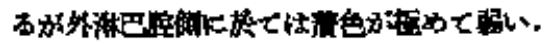

踏:

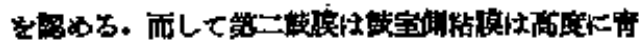

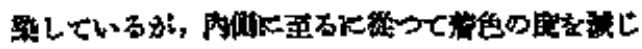

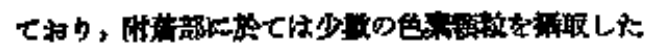

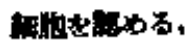

7.

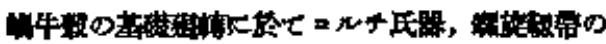

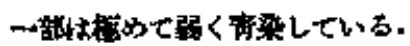

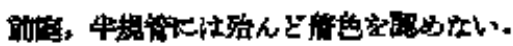

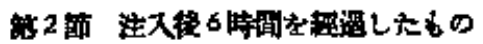
(No. 97)

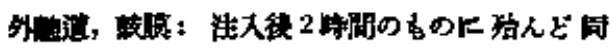
モである.

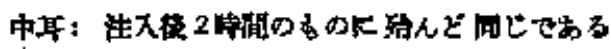

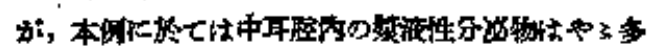

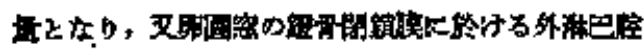

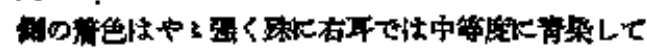
W.

\section{if :}

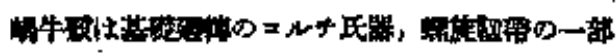

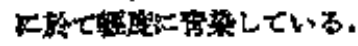

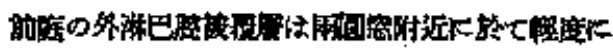
莆整している.

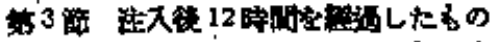
(No. 119, No.143 右聑)

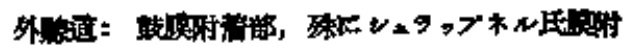

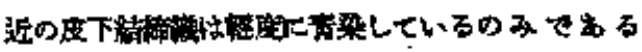

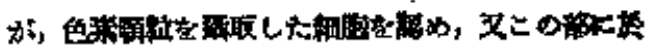

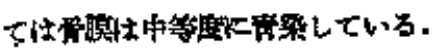

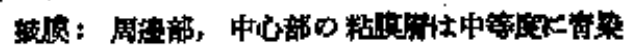

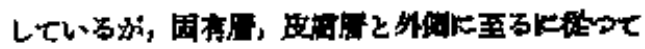

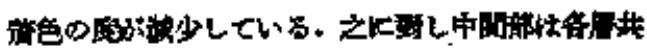

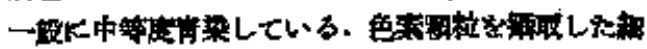

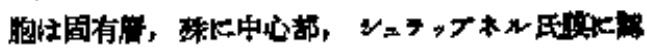
められ苛。

\section{中 F;}

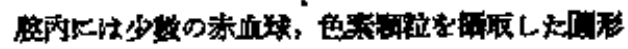

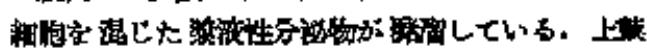

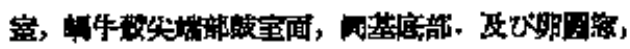

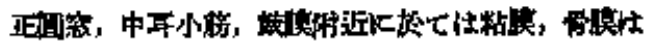

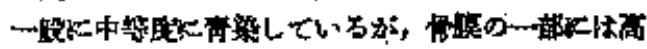

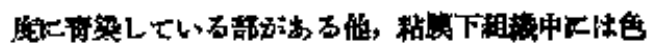

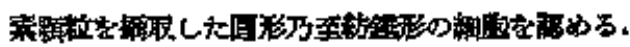

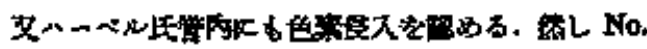

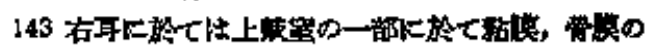

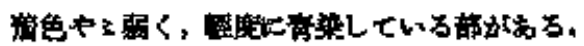

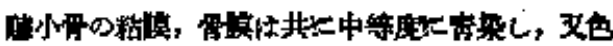

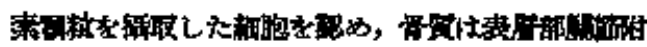

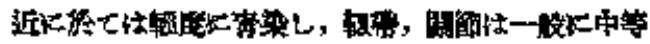

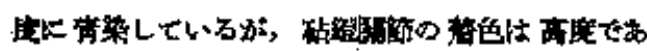

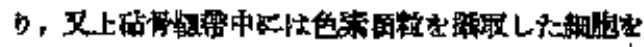

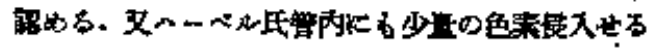
のをめな.

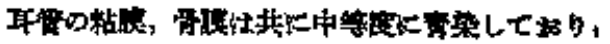

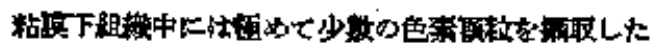

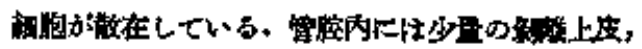

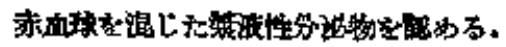

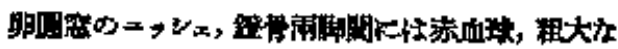

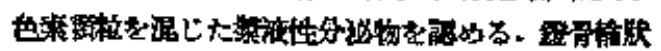

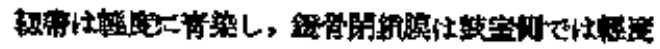

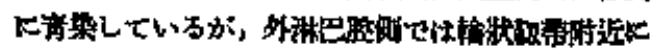

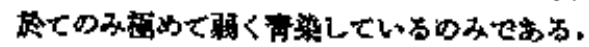

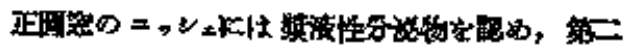

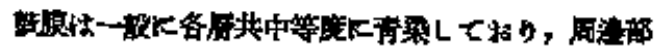
$1-56$ 


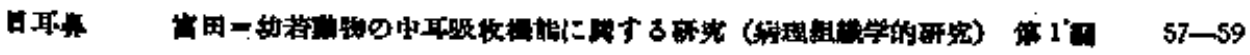

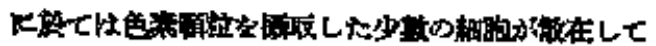
い古.

19:

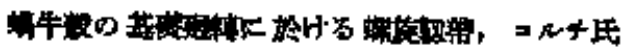

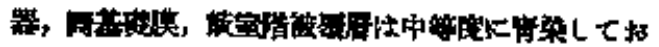

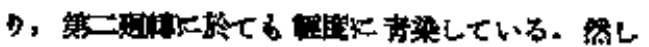

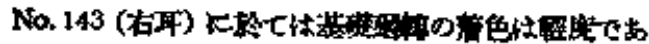

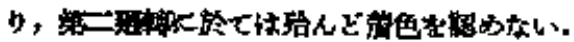

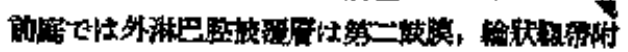

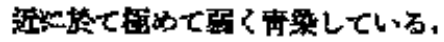

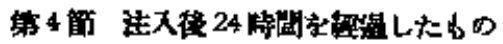
(No, 104, No. 103 右耳)

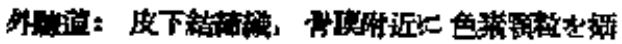

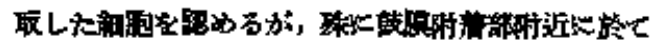

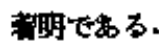

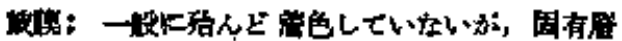

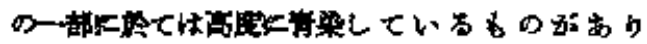

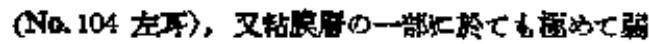

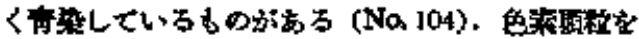

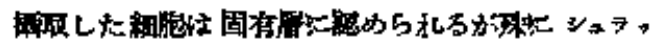

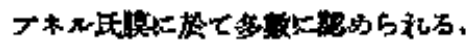

中“于s

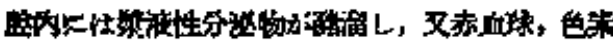

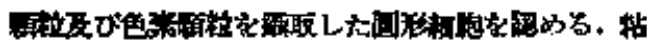

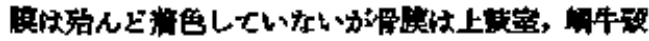

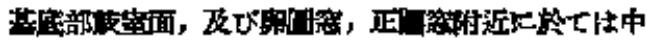

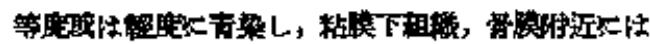

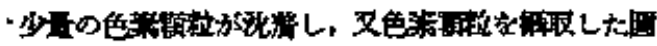

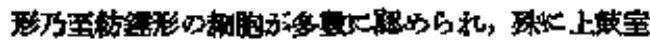

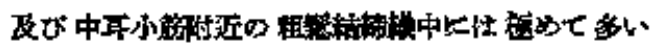

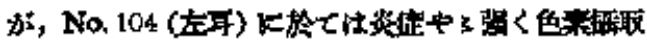

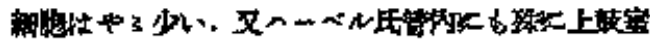

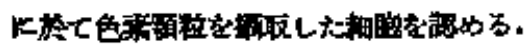

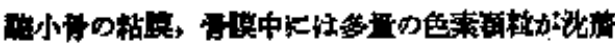

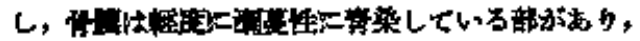

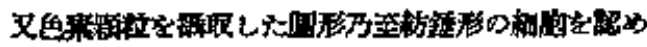

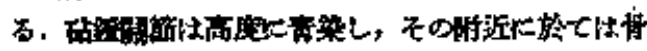

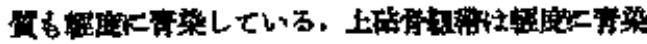

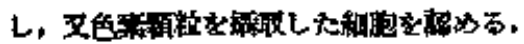

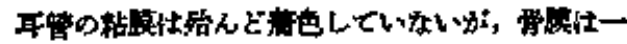

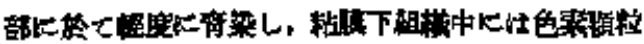

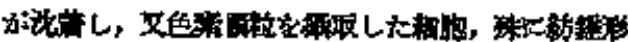

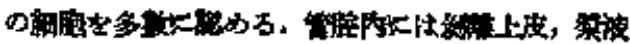

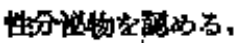

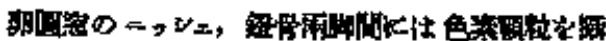

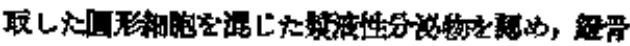

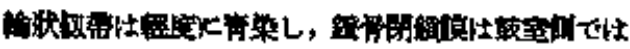

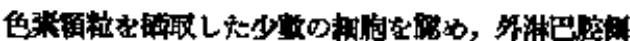

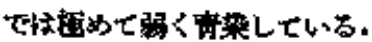

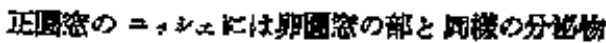

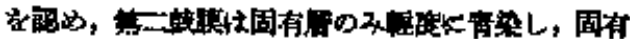

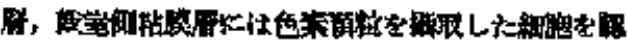

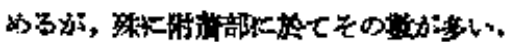

内 而:

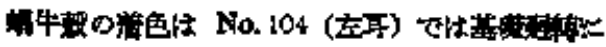

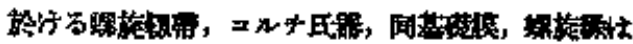

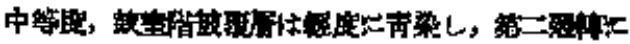

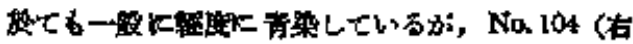

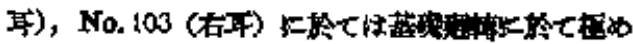

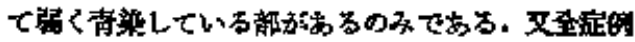

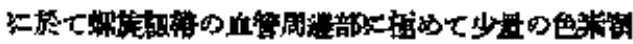

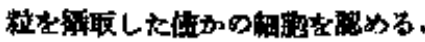

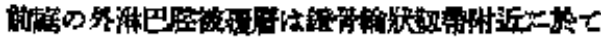

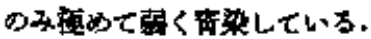

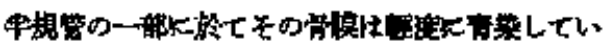
(No. 104 右年).

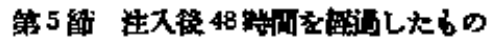
(No. 85)

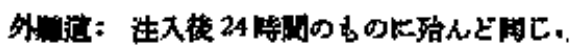

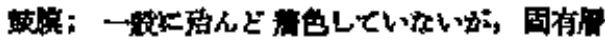

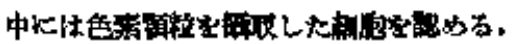

中 F:

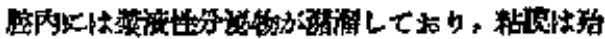

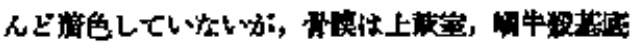

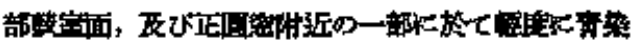

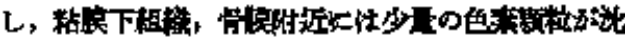

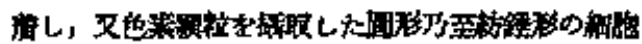

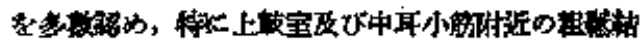

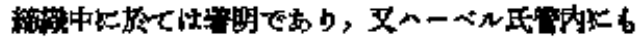

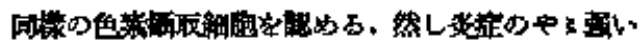

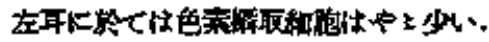

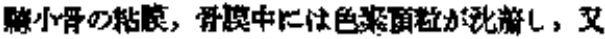




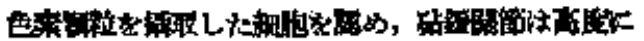

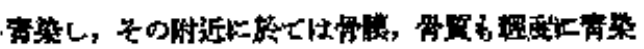

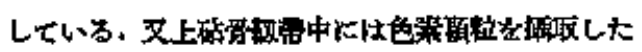

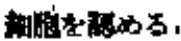

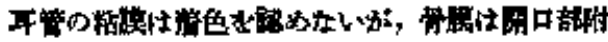

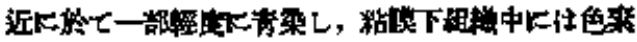

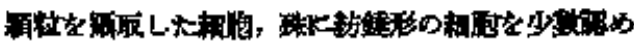
3.

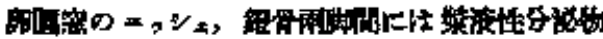

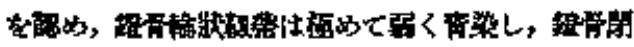

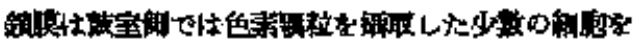

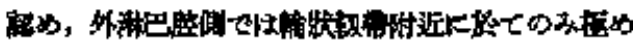

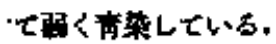

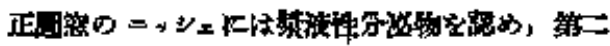

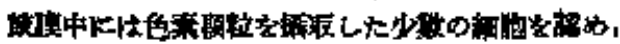

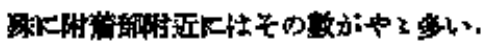

两 茞:

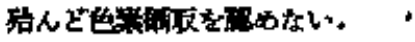

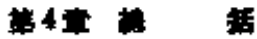

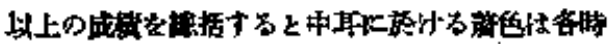

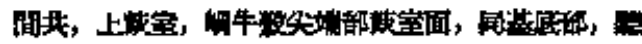

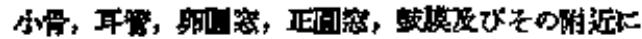

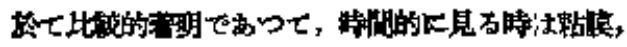

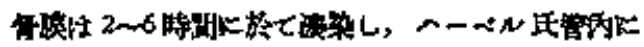

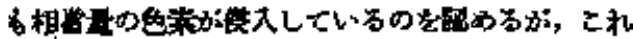

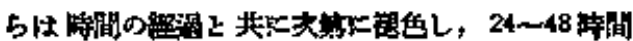

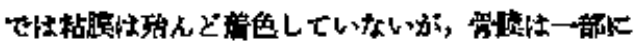

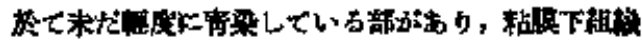

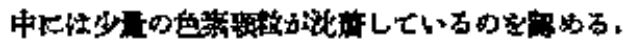

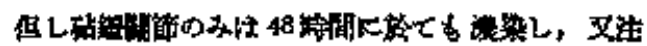

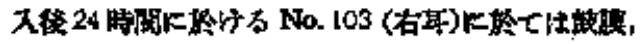

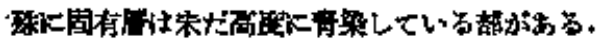

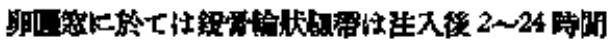

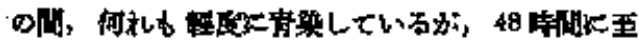

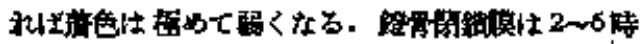

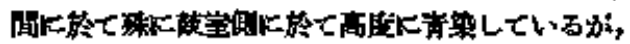

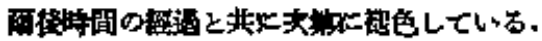

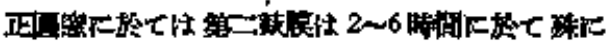

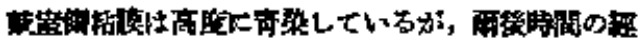

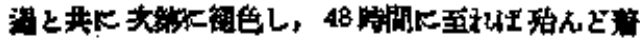

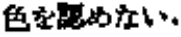

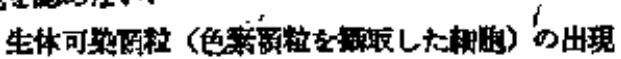

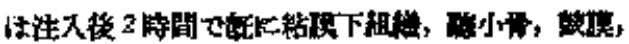

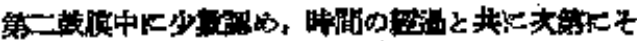

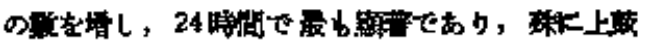

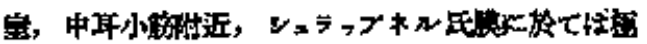

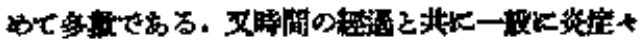

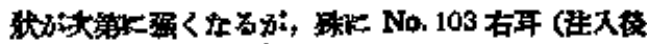

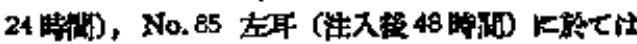

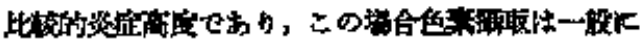

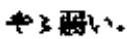

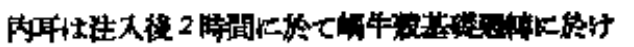

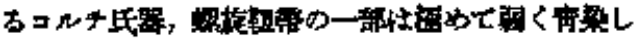

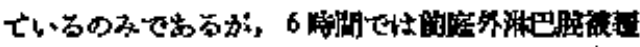

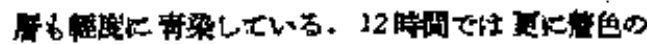

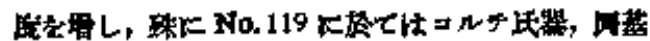

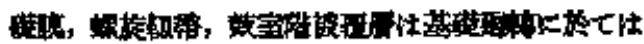

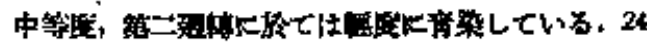

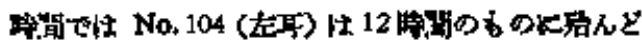

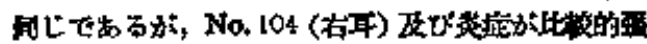

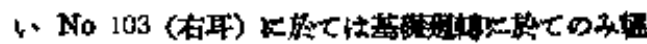

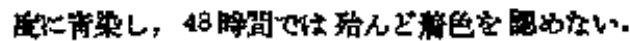

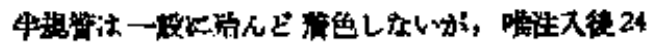

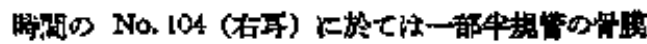

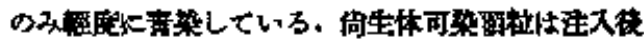

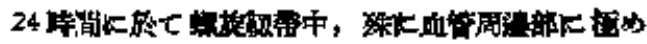

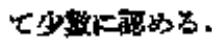

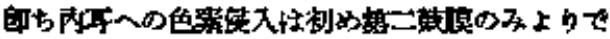

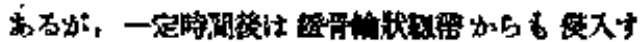
¿.

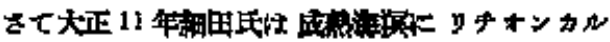

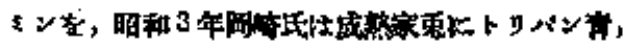

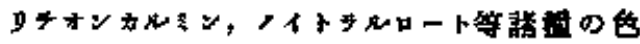

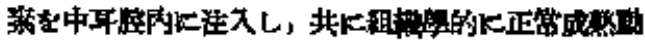

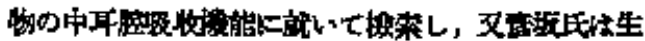

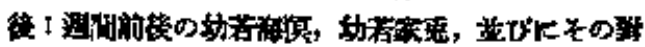

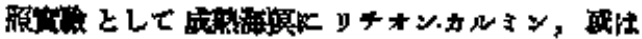

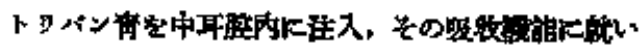

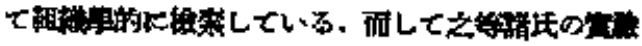

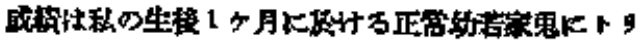

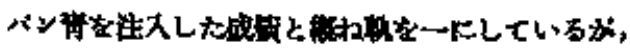




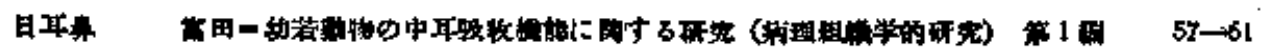

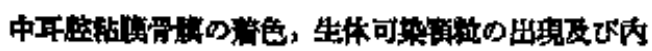

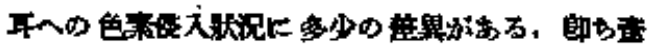

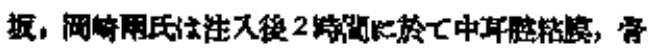

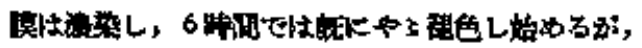

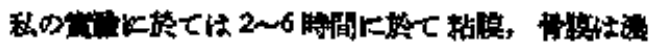

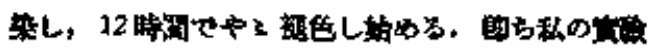

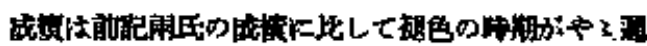

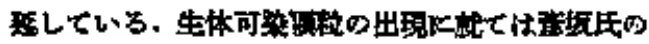

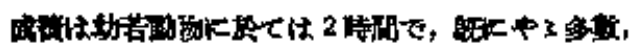

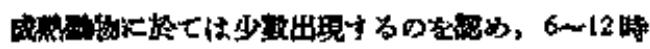

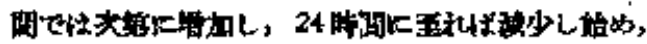

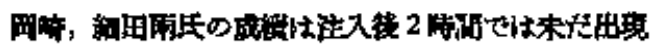

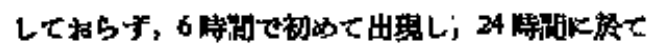

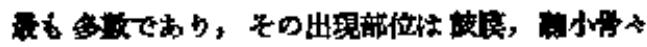

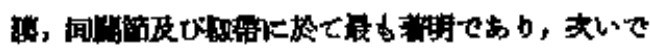

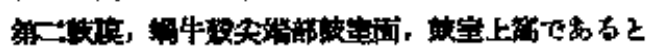

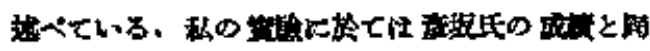

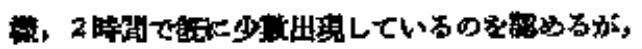

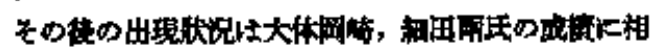

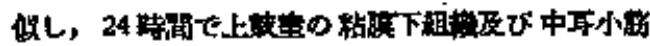

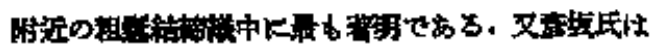

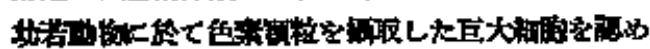

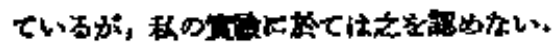

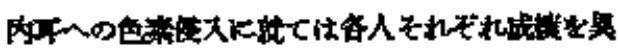

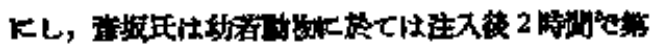

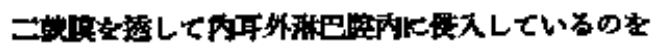

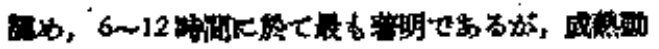

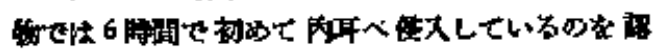

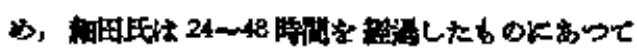

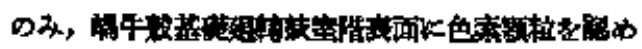

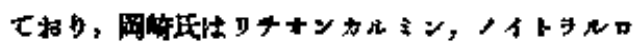

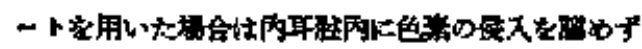

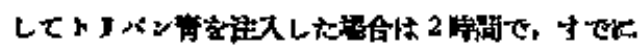

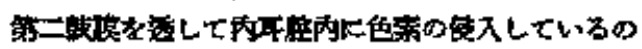

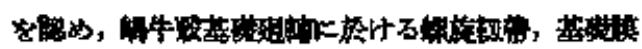

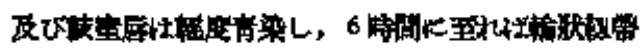

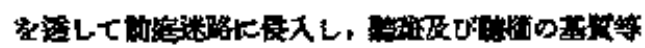

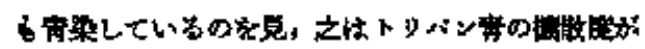

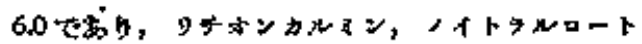

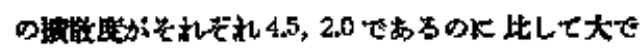

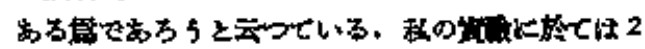

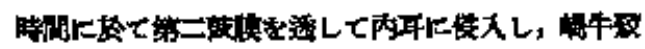

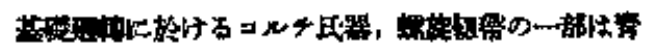

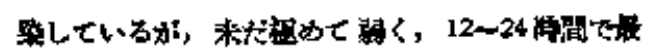

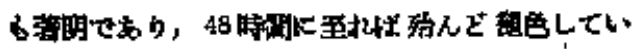
3.

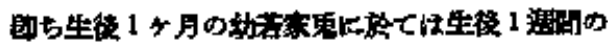

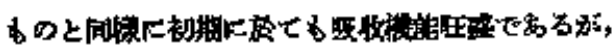

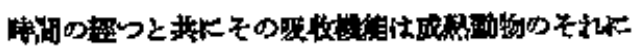

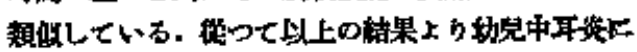

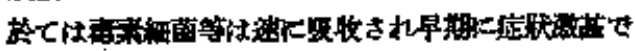

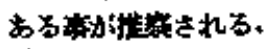

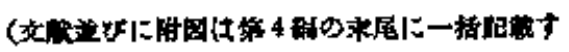
t),

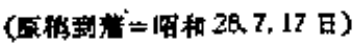

